\title{
MECHANICAL PROPERTIES AND SET RECOVERY OF COMPRESSED POPLAR WITH GLYCERIN PRETREATMENT
}

\author{
Bo-Han Xu, Ke Liu \\ Dalian University of Technology \\ Dalian, People's Republic of China \\ Abdelhamid Bouchaїr \\ Universite Clermont Auvergne \\ Clermont-Ferrand, France \\ (Received May 20i9)
}

\begin{abstract}
In order to improve the mechanical properties of low-density wood, the densified wood was fabricated. Northeast China fast-growing poplar was firstly immersed in $50 \%$ glycerin for $24 \mathrm{~h}$, and then compressed under $150^{\circ} \mathrm{C}$ to attain $60 \%$ compression ratio with different thermal modification time $(0.5,1$, and $2 \mathrm{~h})$. The set recovery, modulus of elasticity (MOE), modulus of rupture (MOR) and hardness of compressed wood were tested to assess the influence of thermal modification time and wet/dry cycles on mechanical properties and set recovery of compressed poplar with glycerin pretreatment. It can be found that the thermal modification time of $1 \mathrm{~h} \mathrm{can}$ be more appropriate, the first wet/dry cycle has a significant effect on mechanical properties and set recovery of compressed wood due to the dilution of glycerin during the soaking.
\end{abstract}

KEYWORDS: Glycerin pretreatment, thermal modification time, wet/dry cycles, mechanical properties, set recovery, poplar.

\section{INTRODUCTION}

The mechanical properties of wood, such as the surface hardness, MOE and MOR, are positively associated with its density (Gong et al. 2010, Rautkari et al. 2011). The density of the wood depends on the cell wall thickness and size of lumen, and the densities of cell wall are approximately the same $\left(1500 \mathrm{~kg} \cdot \mathrm{m}^{-3}\right)$ regardless of the wood species or cell type (Kellogg and Wangaard 1969). Thus, density can be increased by compressing the porous structure in the transverse direction (Laine et al. 2016), when deformations in the densification process are 
largely the result of the viscous buckling of cell walls without major fracture taking place (Kutnar et al. 2008). In general, wood cannot be compressed directly, because cracking may occur. Before compression, wood needs to be softened from a rigid state to a thermoplastic flow state (Wang and Huang 2011). After compression, the densified wood has a tendency to return to its original dimensions, which is known as set recovery (Rautkari et al. 2010), therefore, it is necessary to fix permanently the compressive deformation through some pretreatment methods for uncompressed wood (Rezayati Charani et al. 2007, Li et al. 2013) and post-treatment methods for compressed wood (Laine et al. 2013, Navi and Heger 2004).

The melamine formaldehyde resin or phenol formaldehyde resin impregnation is a pretreatment method widly studied (Inoue et al. 1991, Wallstrom and Lindberg 1999, Yano et al. 2000, Ohmae et al. 2002, Inoue et al. 2007b), which contributes to dimensional stability by swelling the cell wall and forming a rigid cross-linked network upon curing. However, the high cost of resin limits its application in the wood densification processes.

The pretreatment with glycerin is also an alternative process to fabricate the densified wood. As glycerin is adsorbed to hydroxyl groups through hydrogen bonding in amorphous region, wood enters in swollen state and the molecules are easy to slip (Yan et al. 2010). The glycerin can accelerate the degradation of wood component, and form a chemical cross-linkage between molecules of the matrix constituents, which contributes to fix deformation of compressed wood (Yan et al. 2011). In addition, the stress relaxation is also aggravated by glycerin (Yan et al. 2011).

The post-treatment at high temperature after densification is one of common processes used to fix the compressive deformation (Rautkari et al. 2010, Esteves et al. 2017), due to the release of stresses stored in the cell wall polymers by their decomposition and the formation of some cohesive structures (Higashihara et al. 2004). The steam post-treatment is being receiving more attention (Ito et al. 1998, Skyba et al. 2009, Fang et al. 2012, Kutnar and Kamke 2012, Rautkari et al. 2013). However, most deal with thin wood samples due to efficient steam injection (Dwianto et al. 1999, Navi and Heger 2004, Inoue et al. 2007a). The closed steam system limits its appication to batch production. High temperature post-treatment in the absence of steam is also effective in reducing compression-set recovery, due to changes in the polar side groups on the molecular structures of cellulose, hemicelluloses, lignin, and extractives (Hillis 1984, Morsing 2000).

Many attempts have been made to develop a suitable process for the densification of different wood species by assessing the improvements in mechanical properties, dimensional stability and durability (Ulker and Burdurlu 2016, Esteves et al. 2017, Kúdela et al. 2017).

In general, the pretreatment with glycerin and thermal post-treatment are used together to reduce set recovery. Though some studies have reported the mechanical properties and set recovery of compressed wood using those two treatment processes (Yan 2010, Cai et al. 2013), few studies focused on the mechanical properties and set recovery of compressed wood exposed to humid or wet condition, which may destroy the cohesive structures formed in hot treatment. Especially, as the compressed wood is soaked in the water, the glycerin may be diluted, which may affect the mechanical properties and set recovery of compressed wood.

This aim of this paper is to investigate the influence of thermal modification time during densification on mechanical properties and set recovery of compressed poplar with glycerin pretreatment. Northeast China poplar was firstly immersed in $50 \%$ glycerin for $24 \mathrm{~h}$, then compressed under $150^{\circ} \mathrm{C}$ to attain $60 \%$ compression ratio with different thermal modification time $(0.5 \mathrm{~h}, 1 \mathrm{~h}$, and $2 \mathrm{~h})$. In order to assess the impact of moisture changes, the compressed specimens were subjected to five cycles of water soaking and drying, and their mechanical properties and set recovery were compared with those without bearing environmental changes. An analysis of variance (ANOVA) was used to evaluate statistical significance of the parameters, and the result is considered statistically significant for $p<0.05$. 


\section{MATERIALS AND METHODS}

\section{Materials and pretreatment}

The clear specimens without knots, cracks, decay and other visible defects were made from Chinese white poplar (Populus tomentosa) from northeast China, with a length of $600 \mathrm{~mm}$ (longitudinal) and width of $160 \mathrm{~mm}$ (tangential). They were firstly placed in an environmentalcontrolled room $\left(20^{\circ} \mathrm{C}, 65 \%\right.$ relative humidity) until equilibrium moisture content of approximately $12 \%$ was achieved, and then planned to thickness of $45 \mathrm{~mm}$ (radial). The measured wood density was equal to $400 \mathrm{~kg} \cdot \mathrm{m}^{-3}$. After that, the specimens were impregnated in $50 \%$ glycerin solution at $50^{\circ} \mathrm{C}$, which is the optimal concentration to control the set recovery (Yan 2010), for $23 \mathrm{~h}$ and at $100^{\circ} \mathrm{C}$ for $1 \mathrm{~h}$.

\section{Compression process}

The specimens were compressed at $150^{\circ} \mathrm{C}$ with a speed of $10 \mathrm{~mm} \cdot \mathrm{min}^{-1}$ along the radial direction (Fig. 1) to a target thickness of $18 \mathrm{~mm}$ in order to obtain $60 \%$ compression ratio (CR), which can be calculated according to Eq. 1. The wood was densified following the process shown in Fig. 2, and then platens were maintained in the same position for $0.5 \mathrm{~h}, 1 \mathrm{~h}$, and $2 \mathrm{~h}$, respectively, in order to investigate the influence of thermal modification time.

$$
C R=\frac{t_{1}-t_{\mathrm{C}}}{t_{\mathrm{I}}} \times 100 \%
$$

where: $t_{\mathrm{I}}$ is the original thickness $(\mathrm{mm})$, and $t_{\mathrm{C}}$ is the target compressed thickness $(\mathrm{mm})$.
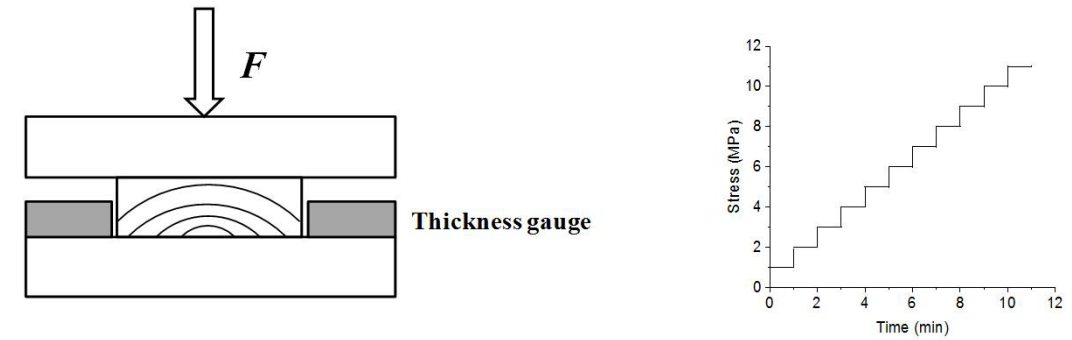

Fig. 1: Schematic diagram of the compression.

Fig. 2: Schematic diagram of the densification process.

\section{Set recovery}

To measure set recovery, the small specimens (50 mm longitudinal, $15 \mathrm{~mm}$ tangential) were cut from compressed wood, which had been conditioned in an environment-controlled room $\left(20^{\circ} \mathrm{C}, 65 \%\right.$ relative humidity) until equilibrium moisture content was achieved. Then, the specimens were dried in a convection oven at $103^{\circ} \mathrm{C}$, and their thickness was measured as $t_{\mathrm{C}}$ $(\mathrm{mm})$. After that, the specimens were soaked in water for $24 \mathrm{~h}$ and again oven-dried, and their thickness was measured as $t_{\mathrm{S}}(\mathrm{mm})$. The percentage of set recovery (SR) can be determined using Eq. 2:

$$
S R=\left[\left(t_{\mathrm{s}}-t_{\mathrm{C}}\right) /\left(t_{\mathrm{I}}-t_{\mathrm{C}}\right)\right] \times 100 \%
$$




\section{Wet/dry cycles}

In order to assess the impact of moisture changes, a process of wet/dry cycles was performed, in which soaking in water for $24 \mathrm{~h}$ and again oven-drying is defined as one wet/dry cycle, and the set recovery and mechanical properties of compressed wood were measured after one, three and five wet/dry cycles.

\section{Mechanical properties}

Before testing, all specimens were firstly conditioned in an environment-controlled room $\left(20^{\circ} \mathrm{C}, 65 \%\right.$ relative humidity) until equilibrium moisture content was achieved. The three-point bending tests for 6 replicates of specimens were performed to measure the modulus of elasticity (MOE) and modulus of rupture (MOR) of compressed wood according to ASTM D143 - 14 (2015). The specimens (Fig. 3) with $312 \mathrm{~mm}$ in length were cut from compressed wood, and the test span is $252 \mathrm{~mm}$ in order to meet a minimum span-to-depth ratio of 14 (ASTM 2015). MOE (MPa) and MOR (MPa) were calculated according to Eq. 3 and Eq. 4 (ASTM 2014):

$$
\begin{aligned}
& \mathrm{MOE}=\frac{p l^{3}}{4 b d^{3} \Delta} \quad(\mathrm{MPa}) \\
& \mathrm{MOR}=\frac{3 P_{\max } l}{2 b d^{2}} \quad(\mathrm{MPa})
\end{aligned}
$$

where: $p$ is the increment of applied load below proportional limit $(\mathrm{N}), P_{\max }$ is maximum load $(\mathrm{N})$, $l$ is the span between the two supports $(\mathrm{mm}), b$ is the width of specimen $(\mathrm{mm}), d$ is the height of specimen $(\mathrm{mm})$, and $\Delta$ is the increment of deflection corresponding to $p(\mathrm{~mm})$.

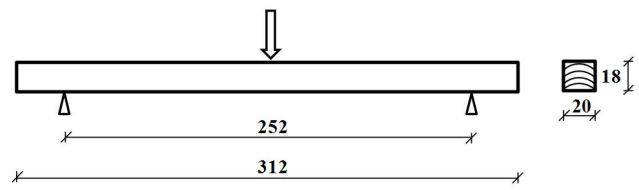

Fig. 3: Schematic diagram of the bending test.

Four replicates of specimens with $150 \mathrm{~mm}$ in length and $60 \mathrm{~mm}$ in width cut from the compressed wood were used to measure Brinell hardness (HB) according to standard EN 1534 (2000) with minor modifications, similar to that carried out by Rautkari et al. (2011). Six points on each sample were tested. A steel ball of $10 \mathrm{~mm}$ diameter $(D)$ is intended in the wood surface at such a rate that maximum load $(F)$ of $1 \mathrm{kN}$ is reached in $15 \mathrm{~s}$, and then the load is held for $25 \mathrm{~s}$, finally the load is released over a period of $15 \mathrm{~s}$. Because it is difficult to measure accurately the diameter of the indentation, therefore, the maximum depth of the indentation $\left(b_{\max }\right)$ is adopted, which was measured automatically by the universal testing equipment. The HB is calculated according to Eq. 5:

$$
\mathrm{HB}=\frac{F}{\pi D h_{\max }} \quad(\mathrm{MPa})
$$

Hardness recovery (HR) was also measured using Eq. 6, which represents the percentage of wood recovery directly after indentation:

$$
\mathrm{HR}=\frac{h_{\max }-h_{\mathrm{r}}}{h_{\max }} \times 100 \%
$$

where: $\quad h_{r}(\mathrm{~mm})$ is the recovered indentation after releasing the load. 


\section{RESULTS AND DISCUSSION}

\section{Influence of thermal modification time}

The set recovery of compressed wood with different thermal modification time is illustrated in Fig. 4. With the increase of thermal modification time, the set recovery decreases. The set recovery for compressed wood with the thermal modification of $1 \mathrm{~h}$ and $2 \mathrm{~h}$ is much less than that for specimens with the thermal modification time of $0.5 \mathrm{~h}$. The set recovery at various thermal modification times $(p=0.000)$, shows highly significant differences, which has also been found in previous studies (Yan et al. 2010).
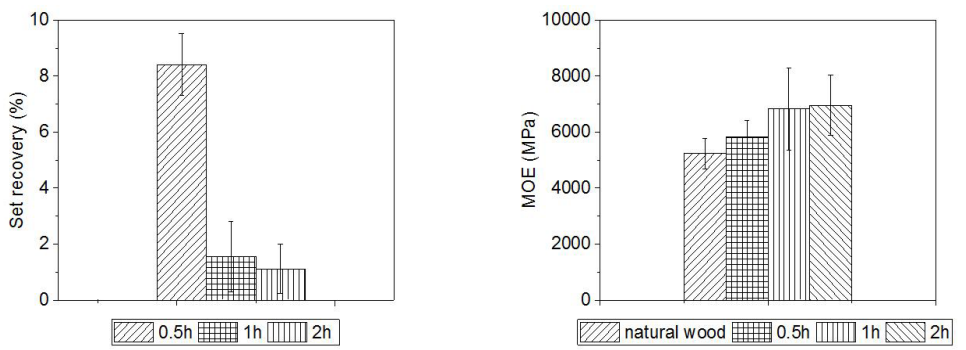

Fig. 4: Set recovery of compressed wood with Fig. 5: MOE of specimens. different thermal modification time.

The density of compressed wood can be up to $1000 \mathrm{~kg} \cdot \mathrm{m}^{-3}$. The MOE and MOR of compressed wood with different thermal modification time and those of natural wood are illustrated in Figs. 5 and 6.

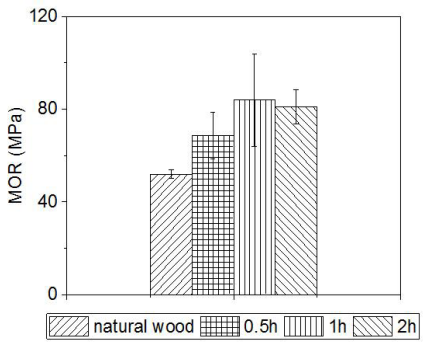

Fig. 6: MOR of specimens.

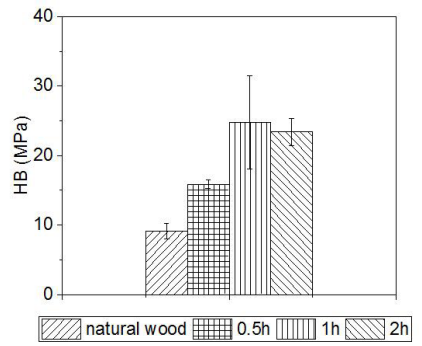

Fig. 7: Brinell Hardness of specimens.

The $\operatorname{MOE}(p=0.183>0.05)$ and $\operatorname{MOR}(p=0.156>0.05)$ at various thermal modification times, are not statistically significant. However, in previous studies, Yan et al. (2010) found that the MOE at various thermal modification times $(0.5 \mathrm{~h}$ and $1 \mathrm{~h})$, has significant differences.

The HB and HR of specimens are illustrated in Figs. 7 and 8. The HB $(p=0.000)$ and HR $(p=0.000)$ at various thermal modification times, show highly significant differences. The set recovery of compressed wood after wet/dry cycles is illustrated in Fig. 9. The Brinell hardness is highest for specimens with the thermal modification time $1 \mathrm{~h}$. A long thermal modification time may result in the degradation of wood components, which will decrease mechanical properties of wood. The observation is consistent with the previous studies (Yan et al. 2010, Laine et al. 2016). It can be seen that the HR is lowest for the specimens with the thermal modification time of $1 \mathrm{~h}$. These results can imply that the thermal modification time of $1 \mathrm{~h}$ can be more appropriate. 


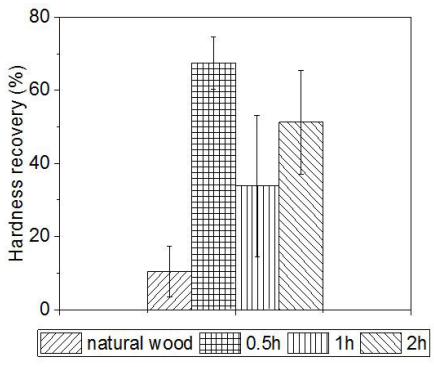

Fig. 8: Hardness recovery of specimens.

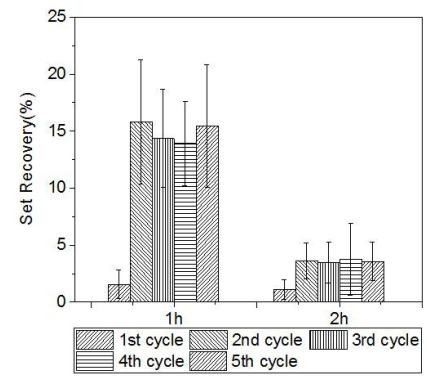

Fig. 9: Set recovery of compressed wood after different wet/dry cycles.

\section{Influence of wet/dry cycles}

Tab. 1 summarizes the $p$-value to present the statistical significance of wet/dry cycle with respect to density, set recovery and mechanical properties of compressed wood. At different wet/dry cycles, only the density, set recovery and HR of compressed wood with the thermal modification time of $1 \mathrm{~h}$ have statistical significance; the density and $\mathrm{HB}$ of compressed wood with the thermal modification time of $2 \mathrm{~h}$ are statistically significant.

Tab. 1: Statistical significance ANOVA, p-value. Units (-).

\begin{tabular}{|c|c|c|c|c|c|c|}
\hline $\begin{array}{c}\text { Thermal } \\
\text { modification time }\end{array}$ & Density & Set recovery & MOE & MOR & HB & HR \\
\hline $1 \mathrm{~h}$ & 0.014 & 0.000 & 0.469 & 0.535 & 0.984 & 0.008 \\
\hline $2 \mathrm{~h}$ & 0.000 & 0.200 & 0.589 & 0.286 & 0.032 & 0.084 \\
\hline
\end{tabular}

After the second wet/dry cycle, the set recovery of compressed wood increases significantly. From the second wet/dry cycle, the set recovery changes rarely. For wood compressed under saturated steam, the set recovery reaches a plateau after the third cycle (Kutnar and Kamke 2012).

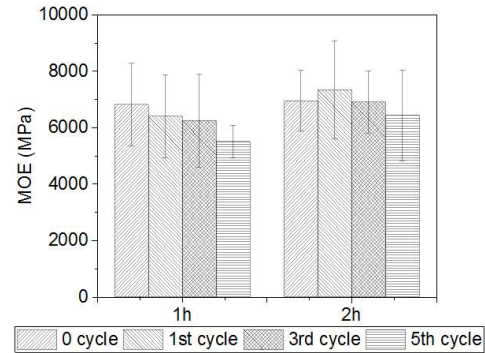

Fig. 10: MOE of compressed wood after different wet/dry cycles.

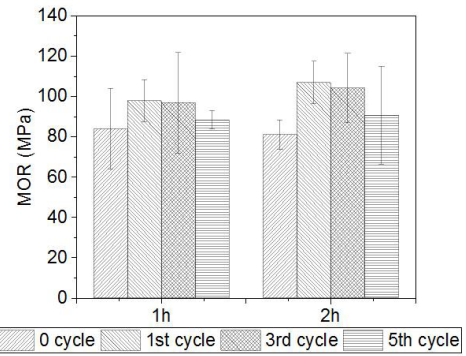

Fig. 11: MOR of compressed wood after different wet/dry cycles.

As shown in Figs. 10 and 11, after the first wet/dry cycle, the MOE and MOR decrease gradually with the increase of wet/dry cycles. For wood compressed under saturated steam, the wet/dry cycle also causes a decrease in the MOE and MOR (Kutnar and Kamke 2012). 


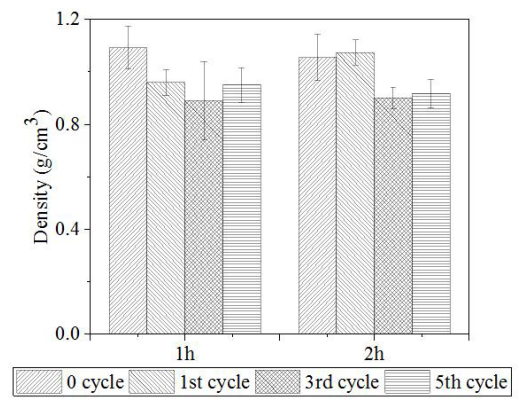

Fig. 12: Density of compressed wood after different wet/dry cycles.

Density of glycerinis equal to $1261 \mathrm{~kg} \cdot \mathrm{m}^{-3}$, which is greater than that of compressed wood. Due to the dilution of glycerin during the soaking, the density of compressed wood decreases (Fig. 12), therefore, the HB of compressed wood also decreases. After the first wet/dry cycle, the $\mathrm{HB}$ of compressed wood with the thermal modification time of $1 \mathrm{~h}$ has nearly no change, and $\mathrm{HB}$ of compressed wood with the thermal modification time of $2 \mathrm{~h}$ decreases gradually with the increase of wet/dry cycle as shown in Fig. 13. Fig. 14 illustrates the HR of compressed wood compressed after different wet/dry cycles, and the first wet/dry cycle significantly results in the increase of HR.

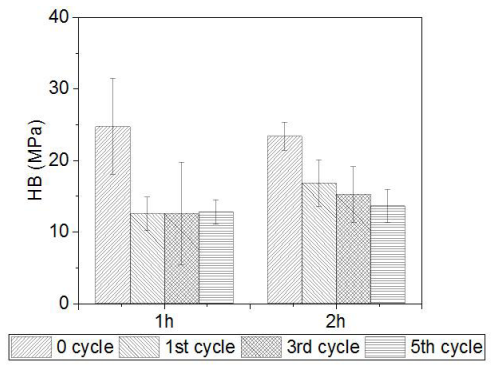

Fig. 13: Brinell Hardness of compressed wood after different wet/dry cycles

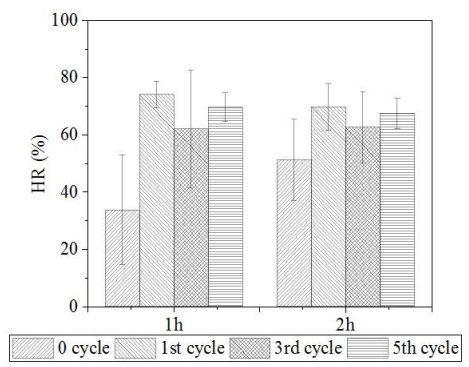

Fig. 14: Hardness recovery of compressed wood after different wet/dry cycles

\section{CONCLUSIONS}

This paper presented the influence of thermal modification time and wet/dry cycles on set recovery and mechanical properties of compressed poplar with glycerin pretreatment. The set recovery decreases with the increase of the thermal modification time, however, the set recovery of compressed wood with the thermal modification time of $1 \mathrm{~h}$ is just slightly higher than that of $2 \mathrm{~h}$. The MOE and MOR at various thermal modification times are not statistically significant. For compressed wood with the thermal modification time of $1 \mathrm{~h}$, the HB is highest and the HR is lowest. In conclusion, the thermal modification time of $1 \mathrm{~h}$ is suitable for compressed wood used in normal condition.

After the second wet/dry cycle, the set recovery of compressed wood clearly increases, and from the second wet/dry cycle, the set recovery of compressed wood changes rarely. The set 
recovery of compressed wood with the thermal modification time of $1 \mathrm{~h}$ is obviously higher than that of $2 \mathrm{~h}$. Thus, compressed wood with the thermal modification time of $2 \mathrm{~h}$ is more appropriate for humid or wet condition, due to the favorable deformation fixation.

After the first wet/dry cycle, the MOE and MOR of compressed wood decrease with the increase of wet/dry cycles. The first wet/dry cycle significantly results in the decrease of the HB and the increase of HR. Therefore, the first wet/dry cycle has significant effect on mechanical properties of compressed wood due to the dilution of glycerin during the soaking.

\section{ACKNOWLEDGEMENTS}

The authors gratefully acknowledge the support of "National Natural Science Foundation of China (No. 51878114)" and "Creative Research Groups of the National Natural Science Foundation of China (Grant No. 51421064)".

\section{REFERENCES}

1. ASTM D198-14, 2014: Standard test methods of static tests of lumber in structural sizes.

2. ASTM D143-14, 2015: Standard test methods for small clear specimens of timber.

3. Cai, J., Yang, X., Cai, L., Shi S.Q. 2013: Impact of the combination of densification and thermal modification on dimensional stability and hardness of poplar lumber. Drying Technology 31(10): 1107-1113.

4. Dwianto, W., Morooka, T., Norimoto, M., Kitajima, T., 1999: Stress relaxation of sugi (Cryptomeria japonica D. Don) wood in radial compression under high temperature steam. Holzforschung 53(5): 541-546.

5. EN 1534, 2010: Wood flooring. Determination of resistance to indentation. Test method.

6. Esteves, B., Ribeiro, F., Cruz-Lopes, L., Ferreira, J.V., Domingos, I., Duarte, M., Duarte, S., Nunes, L., 2017: Densification and heat treatment of maritime pine wood. Wood Research 62(3): 373-388.

7. Fang, C.H., Mariotti, N., Cloutier, A., Koubaa, A., Blanchet, P., 2012: Densification of wood veneers by compression combined with heat and steam. European Journal of Wood and Wood Products 70(1-3): 155-163.

8. Gong, M., Lamason, C., Li, L., 2010: Interactive effect of surface densification and post-heat-treatment on aspen wood. Journal of Materials Processing Technology 210(2): 293-296.

9. Higashihara, T., Morooka, T., Norimoto, M., 2000: Permanent fixation of transversely compressed wood by steaming and its mechanism. Mokuzai Gakkaishi 46(4): 291-297.

10. Hillis, W.E., 1984: High temperature and chemical effects on wood stability. Wood Science and Technology 18(4): 281-293.

11. Inoue, M., Morooka, T., Norimoto, M., Rowell , R.M., Egawa, G., 1991: Permanent fixation of compressive deformation of wood. II. Mechanisms of permanent fixation. Wood Research \& Technical Notes 27(4): 1859-1866.

12. Inoue, M., Norimoto, M., Tanahashi, M., Rowell, R.M., 2007a: Steam or heat fixation of compressed wood. Wood \& Fiber Science 25(3): 224-235.

13. Inoue, M., Ogata, S., Kawai, S., Rowell, R.M., Norimoto, M., 2007b: Fixation of compressed wood using melamine-formaldehyde resin. Wood \& Fiber Science 25(4): 404-410. 
14. Ito, Y., Tanahashi, M., Shigematsu, M., Shinoda, Y., 1998: Compressive-molding of wood by high-pressure steam-treatment: Part 2. Mechanism of permanent fixation. Holzforschung 52(2): 217-221.

15. Kellogg, R.M., Wangaard, F.F., 1969: Variation in the cell-wall density of wood. Wood and Fiber Science 3(3): 180-204.

16. Kúdela, J., Rešetka, M., Rademacher, P., Dejmal, A., 2017: Influence of pressing parameters on surface properties of compressed beech wood. Wood Research 62(6): 939-950.

17. Kutnar, A., Kamke, F.A., Sernek, M., 2008: The mechanical properties of densified VTC wood relevant for structural composites. Holz als Roh- und Werkstoff 66(6): 439-446.

18. Kutnar, A., Kamke, F.A., 2012: Influence of temperature and steam environment on set recovery of compressive deformation of wood. Wood Science and Technology 46(5): 953-964.

19. Laine, K., Rautkari, L., Hughes, M., Kutnar A., 2013: Reducing the set-recovery of surface densified solid Scots pine wood by hydrothermal post-treatment. European Journal of Wood and Wood Products 71(1): 17-23.

20. Laine, K., Segerholm, K., Wålinder, M., Rautkari, L., Hughes, M., 2016: Wood densification and thermal modification: hardness, set-recovery and micromorphology. Wood Science and Technology 50(5): 1-12.

21. Li, L., Gong, M., Yuan, N., Li, D., 2013: An optimal thermo-hydro-mechanical densification (THM) process for densifying balsam fir wood. Bioresources 8(3): 3967-3981.

22. Morsing, N., 2000: Densification of wood-the influence of hygrothermal treatment on compression of beech perpendicular to the grain. Department of structural engineering and materials, Technical university of Denmark, Series R 79, 139 pp.

23. Navi, P., Heger, F., 2004: Combined densification and thermo-hydro-mechanical processing of wood. Mrs Bulletin 29(5): 332-336.

24. Ohmae, K., Minato, K., Norimoto, M., 2002: The analysis of dimensional changes due to chemical treatments and water soaking for Hinoki (Chamaecyparis obtusa) wood. Holzforschung 56(1): 98-102

25. Rautkari, L., Properzi, M., Pichelin, F., Hughes, M., 2010: Properties and set-recovery of surface densified Norway spruce and European beech. Wood Science and Technology 44(4): 679-691.

26. Rautkari, L., Kamke, F.A., Hughes M., 2011: Density profile relation to hardness of viscoelastic thermal compressed (VTC) wood composite. Wood Science and Technology 45(4): 693-705.

27. Rautkari, L., Laine, K., Kutnar, A., 2013: Hardness and density profile of surface densified and thermally modified Scots pine in relation to degree of densification. Journal of Materials Science 48(6): 2370-2375.

28. Rezayati Charani, P., Mohammadi Rovshandeh, J., Mohebby, B., Ramezani O., 2007: Influence of hydrothermal treatment on the dimensional stability of beech wood. Caspian Journal of Environmental Sciences 5(2): 125-131.

29. Skyba, O., Schwarze, F.W.M.R., Niemz, P., 2009: Physical and mechanical properties of thermo-hygro-mechanically (THM)-densified wood. Wood Research 54(2): 1-18.

30. Ulker, O., Burdurlu, E., 2016: Some mechanical properties of densified and laminated lombardy poplar (Populus nigra L.). Wood Research 61(6): 959-970.

31. Wallstrom, L., Lindberg, K.A.H., 1999: Measurement of cell wall penetration in wood of water-based chemicals using SEM/EDS and STEM/EDS technique. Wood Science and Technology 33(2): 111-122. 
32. Wang, Y.W., Huang, R.F., 2011: Research status of wood densification. Forestry Machinery and Woodworking Equipment 39(8): 13-16.

33. Yan, L., 2010: Mechanism and application of compressive deformation fixation of poplar by glycerin pretreatment. Ph.D. Thesis, Beijing Forestry University, China, 118 pp.

34. Yan, L., Cao, J.Z, Jin, X.J., 2010: Deformation fixation, mechanical properties and chemical analysis of compressed Populus cathayana wood pretreated by glycerin. Forestry Studies in China 12(4): 213-217.

35. Yan, L., Cao, J., Gao, W., Zhou, X., Zhao, G., 2011: Interaction between glycerin and wood at various temperatures from stress relaxation approach. Wood Science and Technology 45(2): 215-222.

36. Yano, H., Mori, K., Collins, P.J., Yazaki, Y., 2000: Effects of element size and orientation in production of high strength resin impregnated wood based materials. Holzforschung 54(4): 443-447.

\author{
Bo-Han Xu*, Ke Liu \\ Dalian University of Technology \\ State Key Laboratory of Coastal and Offshore Engineering \\ Ocean Engineering Joint Research Center of Dut-Uwa \\ DaLian ir6o24 \\ People's Republic of China \\ *Corresponding author: bohanxu@dlut.edu.cn
}

\author{
Abdelhamid Bouchä̈r \\ Universite Clermont Auvergne \\ Cnrs, Sigma Clermont \\ Institut PAscal, F-6300o \\ Clermont-Ferrand \\ France
}

